\title{
La «innovación escondida» de las pymes industriales en el capitalismo español. Gestión, estrategias y repertorios de prácticas innovadoras en pymes manufactureras catalanas
}

\author{
Alejandro Pizzi \\ Universidad de Valencia. Departamento de Sociología y Antropología Social \\ alejandro.pizzi@uv.es \\ Manuel Ahedo \\ Universidad de Copenhague. Departamento de Sociología \\ mahe@soc.ku.dk
}

Recepción: 01-06-2018

Aceptación: 02-10-2018

Publicación: 30-09-2019

\section{Resumen}

Las pymes industriales dinámicas e innovadoras son una de las bases de prosperidad colectiva en algunos países y regiones europeas. Desde una sociología multinivel que integra los niveles micro (empresarial-organizativo), meso (regional-local y sectorial) y macro (capitalismo estatal-nacional) dentro del sistema de redes-cadenas de producción del capitalismo global, el artículo analiza la actividad innovadora de las pymes industriales, la cual se puede denominar innovación escondida al no aparecer en los indicadores convencionales de innovación. En base a 22 entrevistas semiestructuradas a directivos de pymes manufactureras de Cataluña, se aplica la Teoría Fundamentada para construir categorías descriptivas y proposiciones conceptuales de cara a comprender las relaciones sociales y los procesos típicos que utilizan las pymes para innovar. Se analizan tres aspectos: los marcos discursivos-cognitivos, las prácticas de planificación y gestión, y las principales estrategias y repertorios de prácticas innovadoras. Las principales aportaciones del artículo son las siguientes. A nivel micro, las formas de participación en la red-cadena de provisión-valor sectorial en la que operan las pymes ejercen una influencia decisiva sobre sus repertorios de innovación, y se han encontrado dos repertorios típicos de prácticas de innovación: las prácticas relativamente autónomas y las prácticas subordinadas a los clientes. A nivel meso del sistema de innovación y empresarial de Cataluña, se han encontrado problemas en la generación de bienes colectivos de competitividad local, debido a aspectos institucionales y a políticas públicas. A nivel macro, el capitalismo español presenta un bajo desarrollo de factores institucionales de capacitación para la innovación en su sistema empresarial.

Palabras clave: sistemas de innovación; capitalismo; redes de provisión-producción; políticas de apoyo a las pymes; bienes colectivos de competitividad local 
Abstract. The 'hidden innovation' of industrial SMEs in Spanish capitalism: Management, strategies and repertoires of innovative practices in Catalan manufacturing SMEs

Innovative and dynamic manufacturing SMEs have been and continue to be one of the bases of collective prosperity in various European countries and regions. Based on a multilevel sociology that integrates the micro level (firm and organization), meso level (regionallocal and sector) and macro level (state-related national capitalism), the article analyses the innovation activity of industrial SMEs, which may be called hidden innovation because it does not appear in conventional indicators. Based on 22 semi-structured interviews with managers of manufacturing SMEs of Catalonia, Grounded Theory is applied to construct descriptive categories and conceptual propositions in order to understand and analyse the social relations and typical processes SMEs use to innovate. Three main issues are analysed: discursive-cognitive frameworks, management and planning, and strategies and repertoires of innovation practices. The main contributions are as follows. At the micro level, the participation of SMEs in the sector-related value-supply chain or network exerts a decisive influence on their innovation repertoires, and two typical repertoires of innovation practices have been found: relatively autonomous practices and client-dependent practices. At the meso level of Catalonia's innovation and business system, problems have been found in producing local collective competition goods due to institutional aspects and public policies. At the macro level, Spain's capitalism displays a low development of institutional factors to provide its business system with innovation capacities.

Keywords: innovation system; development; capitalism; production-supply networks; SME-supporting policies; local collective competition goods

\section{Sumario}

\section{Introducción}

2. Marco teórico

3. Diseño metodológico

4. Marcos discursivo-cognitivos y tipos principales de innovación

5. La planificación y la gestión de la innovación
6. Estrategias y repertorios de prácticas innovadoras

\section{Conclusiones}

Referencias bibliográficas

Anexo de empresas entrevistadas

\section{Introducción}

Las pymes industriales, que incluyen organizaciones con distintos niveles de innovación económica, han sido y siguen siendo una de las bases de la prosperidad socioeconómica en algunos países y regiones, al menos en la Europa occidental. ${ }^{1}$ Sin embargo, en el capitalismo actual las pymes industriales se encuentran ante nuevos problemas, dado que el sistema dominante de producción pivota cada vez más sobre la gran empresa nacional, transnacional y

1. En las épocas recientes se ha identificado un número variante de regiones en los países nórdicos (Kristensen y Lijla, 2011), Alemania, Países Bajos, Italia, etcétera. En España destaca el caso de la Comunidad Autónoma del País Vasco, y en menor medida la Comunidad de Navarra. 
multinacional. Esas grandes empresas, desde una posición jerárquica, gestionan en cascada una red o sistema de proveedores de medianas y pequeñas empresas subcontratadas tradicionalmente enmarcadas en sistemas locales de producción (Crouch, et al., 2001). En este modelo crecientemente dominante, las pymes manufactureras se enfrentan ante dos retos en dos niveles diferentes. Primero, el aprovechamiento de sus capacidades y potencialidades organizativas internas relacionadas con la gestión del trabajo, con el fin de producir mejoras y desarrollos en productos y procesos (Arundel, et al., 2007). Segundo, la colaboración entre ellas y con otras instituciones y organizaciones civiles y públicas para la generación de bienes colectivos de competitividad local (Crouch, et al., 2001; Ahedo, 2010). Las dos cuestiones son clave para la capacidad de una pyme de relacionarse con las grandes empresas clientes y/o líderes en sectores y productos. Este artículo se centra en las prácticas organizativas y de gestión empresarial en pymes manufactureras que tienen por objetivo promover innovaciones y mejoras en productos y procesos, principalmente dentro de su relación con grandes empresas clientes.

Las formas y los procesos de innovación en pymes no han sido una cuestión suficientemente estudiada desde la sociología y otras ciencias sociales afines. Edwards, Delbridge y Munday (2005) hacían una invitación a su estudio desde un renovado enfoque en los procesos de mejoras graduales o incrementales. Generalmente, en la literatura sobre innovación ha habido dos opciones conceptuales: proponer otra noción para la realidad de las pymes o ampliar la definición de innovación. La segunda opción ha sido la habitual, dado el peso institucional del concepto de innovación, el cual ha sido objeto de un constante alargamiento y complejización para poder incluir nuevas realidades. Inicialmente, innovación fue sinónimo de cambio técnico de carácter radical. Luego se fue reconociendo su carácter de mejoras incrementales (progresivas) en procesos, productos, organización, etcétera. En esta opción de ampliar la definición surge el concepto de innovación escondida, dado que no constituye un proceso visible desde la óptica original y convencional (Hansen y Serin, 1997). La innovación escondida comprende un amplio abanico de mejoras, desarrollos, cambios y modificaciones incrementales en productos y procesos, con una alta orientación al mercado o hacia los clientes (Arundel, et al, 2008). Puede ser una innovación efectiva y eficiente, pero no dispone del estatus y el reconocimiento que tiene la innovación radical en los discursos oficiales e institucionales.

Para observar y aprehender esas dinámicas de innovación escondida, resulta útil usar enfoques cualitativos, tal como se propone en este artículo. Por ejemplo, las entrevistas con gerentes de las empresas, directivos y responsables de las mejoras o cambios técnicos permiten reconstruir el marco cognitivo, las lógicas y los incentivos que impulsan las prácticas de innovación, y conocer cómo funciona la innovación de las pymes industriales en sus contextos sistémicos e institucionales. A partir de esta propuesta, el artículo tiene la siguiente estructura. En la segunda sección se presenta el marco teórico que integra los siguientes niveles: global, macro, meso y micro; y propone la hipótesis del estudio. En la 
tercera sección se presenta el abordaje metodológico para analizar la innovación en pymes manufactureras. El análisis se presenta en las siguientes secciones. En la cuarta, se destacan los elementos centrales del discurso empresarial sobre innovación, como marco cognitivo en el que operan los responsables de estas empresas y los principales tipos de innovación en las pymes. En la quinta se analizan las formas típicas de planificación y gestión de la innovación. En la sexta se identifican los repertorios de prácticas innovadoras, en base a rearticulaciones de los elementos desarrollados anteriormente. En las conclusiones se recogen los argumentos más importantes y se relacionan con el marco teórico.

\section{Marco teórico}

Antes de teorizar los niveles micro, meso y macro que afectan las pymes industriales catalanas, es necesario conceptualizar la realidad ontológica del capitalismo global actual, cada vez más transnacionalizado y globalizado, de la mano de grandes empresas de las zonas principales del capitalismo global. Según la perspectiva de los sistemas mundiales, originalmente desarrollada por Wallerstein, y con diferentes actualizaciones (Babones, 2015), las cadenas de producción mundial son gestionadas por empresas lead de países centrales en la zona del Atlántico Norte, que integran piezas, módulos o elementos producidos en zonas marginales de los países centrales o en zonas/países semiperiféricos, o en el caso de materias primas, principalmente en países periféricos del sur global. Dentro de la histórica división internacional del trabajo entre regiones o países centrales, semiperiféricos y periféricos, en las últimas décadas se ha dado una creciente tendencia a la internacionalización, a la financiarización de la propiedad empresarial y a la reestructuración sectorial, especialmente en industria y servicios. Uno de los motores de estas tendencias ha sido el continuo flujo transnacional de inversión y de producción por parte de las grandes empresas de los países centrales.

Las relaciones de provisión o suministro transnacionales entre pymes y empresas de niveles superiores han sido estudiadas desde varios enfoques. De cara a la gestión de la provisión por parte de la empresa cliente o lead, Gereffi, et al. (2005) proponen cinco tipos de relación entre proveedores y empresas superiores en lo que denominan la cadena de valor global: a) de transacción o de mercado: los clientes y proveedores realizan transacciones pero no interactúan; hay pocas posibilidades de innovación para las pymes que proveen suministros a clientes mayores; b) de dominio o de captura: los compradores globales que controlan la cadena de valor ejercen dominio sobre las marcas, diseños, marketing, y una relación exclusiva en la que las pymes están cautivas de los grandes compradores superiores o finales; esta opción también ofrece pocas oportunidades para innovar; c) relacional: en las cadenas relacionales los proveedores realizan más actividades por sí mismos, tienen más compradores potenciales y más opciones de mercado; se dan condiciones para que clientes y proveedores desarrollen más interacciones, lo cual permite un flujo mayor de conocimientos tácitos; d) modular: los proveedores modulares están 
especializados en componentes de productos finales (módulos), que venden a más clientes; en esta relación las pymes, en tanto proveedoras, tienen claras oportunidades para innovar; e) jerárquica o de integración vertical: cuando una empresa lead posee un proveedor especializado y fidelizado, hay más oportunidades de que la gran empresa apoye sus procesos de innovación; en este tipo las posibilidades de innovar para las pymes son las más elevadas.

Bair (2008) realiza varias críticas a la tipología de Gereffi et al. (2005): a) no tiene suficientemente en cuenta las relaciones de poder asimétricas entre las empresas: b) silencia el papel de las instituciones próximas a las empresas, tanto las lead como las locales suministradoras; en el caso las pymes suministradoras hay que tener en cuenta el papel de instituciones locales para generar bienes colectivos de competitividad que pueden ayudar a una pyme local proveedora a optar por un tipo u otro de relación; c) cuestiona el uso político y sesgado de la idea de cadena de valor; d) propone el concepto de red global de producción. Desde esta perspectiva de las redes de producción o de cadenas de valor, suministro o provisión, se enfatiza que las oportunidades para realizar innovaciones dependen del modo de gestión de las cadenas de valor por parte de las empresas lead, a modo de compradores o clientes globales. Cada uno de estos tipos supone para una pyme proveedora un marco de interacción diferente y un marco de opciones y posibilidades de cara a hacer mejoras o innovaciones. En nuestro estudio observamos que, además de las oportunidades, también las estrategias y los repertorios típicos de prácticas de innovación están en función de los modos de gestión de las redes y/o cadenas de valor y suministros.

Las instituciones relevantes que influyen sobre las actividades de innovación económica se registran en tres niveles: el nivel macro, relativo a los sistemas nacionales de innovación; el nivel meso, vinculado con los contextos locales y sectoriales; y el nivel micro, referente a los factores organizativos internos de las empresas. A continuación mencionamos las aportaciones académicas para cada uno de estos niveles que nos resultan significativas para este trabajo, teniendo en cuenta los estudios internacionales y los referidos a España en particular.

$\mathrm{Al}$ nivel macro, y referido al contexto internacional, en la literatura reciente se han identificado varios tipos de capitalismos o de organización de las economías de mercado, con una mayor o menor atención a las diferencias nacionales. Las taxonomías convencionales van desde una tipología dual básica de las economías del Atlántico Norte (de mercado liberal y de mercado coordinado); de tres o cuatro tipos en la Europa occidental (liberal, coordinado, socialdemócrata y del sur de Europa), de cinco o más, incluyendo el modelo de mesocorporatista de grupo empresarial de Asia oriental, y el jerárquico de Latinoamérica (Amable, 2003; Boyer, 2005); o una tipología de seis tipos ideales de sistemas empresariales existentes en un amplio número de países occidentales (Whitley, 1999). Crouch (2005) opina que el fuerte ejercicio de tipologización debilita la necesaria labor analítica de las particularidades nacionales o regionales, ya que es posible encontrar en sectores, regiones o localidades modelos de crecimiento diferentes del modelo nacional dominante; estos casos ejemplifican la complejidad del funcionamiento institucional y provocan incoherencias creativas o 
complementariedades institucionales más por diferencia que por coherencia o similitud. En esa línea de enfatizar la diversidad, Kristensen y Lijla (2011) comparan de forma comprensiva las similitudes y diferencias de los capitalismos nórdicos, con relación a sus desarrollados estados de bienestar.

Asimismo, el enfoque de los sistemas nacionales de innovación (Nelson, 1993; Lundvall, 2007) complementa las posibilidades analíticas al plantear un abordaje centrado en el estado-nación en el contexto internacional, en el que diversas instituciones nacionales y también algunas extranjeras o internacionales (especialmente las financieras) ejercen un efecto conjunto sobre el comportamiento innovador de las empresas. La comparación de sistemas de innovación se ha decantado por dos grandes tipos de sistemas: Science-Technology-Innovation (STI) y Doing-Using-Interacting (DUI) (Lundvall, et al., 2008). El modelo STI se basa en una visión linear y formal de la innovación. Es típico de países con economías basadas en sectores de alta tecnología y empresas de mayores dimensiones, y se fundamenta en conocimientos codificados, personal científico interno y relaciones con instituciones científico-tecnológicas externas. En el modelo DUI, típico de países con menos sectores de alta tecnología y un mayor número de pymes, la innovación se apoya en un proceso reflexivo y dialógico, enfatiza los procesos de abajo-arriba no lineares, informales y multidireccionales de aprendizaje y flujos de conocimiento. Dentro de la visión DUI, se ha dado una creciente importancia a la organización del trabajo. Arundel et al. (2007) relacionan la innovación organizativa, la gestión de recursos humanos y algunos aspectos del mercado de trabajo para los países de la Unión Europea (UE)-15, y proponen cuatro tipos de organización del trabajo: organización que aprende, organización ligera, taylorismo y organización tradicional, que coinciden con otros indicadores de innovación.

Con respecto a la dimensión macro del capitalismo y del sistema de innovación en España, se suele hablar de un modelo típico del sur de Europa, en el que el Estado y el gobierno central, con bajos niveles de efectividad en sus políticas públicas, y las grandes empresas lideran un modelo altamente jerárquico en relación con los otros actores y sectores más débiles, como son las pymes, los sindicatos y los empleados, y las instituciones públicas locales. El sector industrial español es comparativamente pequeño y de menor relevancia que el promedio de la Europa occidental. Presenta asimismo problemas de competitividad internacional, en buena parte debido a las fallidas políticas industriales y laborales que se llevaron a cabo desde la transición a la democracia y en las décadas posteriores. El sistema español de investigación e innovación pivota sobre una relativamente alta actividad de investigación básica mayormente con financiación pública, y una relativamente baja actividad innovadora por parte de las empresas, independientemente de su tamaño y sector de actividad. En el estudio comparado de la UE-15 de Arundel et al. (2007), el sistema de organización del trabajo de España presenta una elevada presencia de organizaciones ligeras y de bajo aprendizaje, así como de organizaciones tayloristas y tradicionales, y una menor presencia de organizaciones que aprenden. Sus datos son consistentes con el modelo dominante de empresario-propietario- 
autoritario, poco proclive a nuevas tendencias de gestión de recursos humanos y a la participación de los empleados en la organización del trabajo.

En el plano internacional, según la literatura que analiza el nivel meso, la actividad productiva e innovadora en pymes está altamente enmarcada en los contextos regionales-locales y sectoriales (Crouch, et al., 2009). En los contextos regionales-locales, principalmente a través de distritos o clusters industriales, las relaciones de coordinación y cooperación entre las pymes, y las relaciones individuales y colectivas con los agentes externos son uno de los factores clave para la innovación en las pymes. Crouch et al. (2001) definen los bienes colectivos de competitividad local (BCCL) como un conjunto de ventajas y recursos colectivos de dos tipos: intangibles, en forma de recursos cognitivos y normativos, y tangibles, en forma de infraestructuras y servicios. Las formas de creación y gobierno de esos bienes colectivos pueden ser diversas, pero destacan las organizadas de forma pública (gobiernos) o privada (asociativa o comunitaria), y son de vital importancia las público-privadas, que combinan las dos (Ahedo, 2010). Ámbitos clave en la generación de estos BCCL son los mercados de trabajo, el capital humano y los sistemas de formación locales, los cuales fueron enfatizados especialmente en la literatura sobre distritos industriales en los años 1980 y 1990, pero paradójicamente son algunas de las áreas menos investigadas en la literatura sobre sistemas de innovación (Asheim et al. 2010). En otras palabras, las relaciones externas en un contexto o marco relacional abierto son clave para las pymes (Lee et al. 2010). Sin embargo, los contextos sectoriales son también relevantes. Algunos autores han subrayado el papel institucional de los colectivos ocupacionales y profesionales sectoriales (Lam, 2002), que vinculan el sistema laboral y de formación con la actividad productiva en las empresas. Las redes de colaboración profesional son un elemento importante en los sistemas sectoriales de innovación (Malerba, 2004), junto al tipo de conocimiento que cada sector posee (Asheim y Coenen, 2005): sintético (sectores ingenieriles o de base tecnológica) o analítico (sectores con una base más científica). En suma, las diferentes relaciones sociales e institucionales de producción y de innovación a nivel regional-local y sectorial son factores clave en la capacidad de innovación y de hacer mejoras de las pymes.

En cuanto al nivel meso en España, el concepto de sistema regional de innovación ha sido profusamente aplicado (Olazarán y Otero, 2009; RES, 2016), en parte motivado por el desarrollo de políticas industriales y de I+D de las comunidades autónomas. Sin embargo, pocas comunidades autónomas han desarrollado sistemas e instituciones de apoyo a la innovación y la competitividad de las pymes. Destacan dos comunidades autónomas. En la comunidad del País Vasco, sus diversas políticas industriales han tenido siempre bastante presente la importancia de las pymes industriales, como en el caso de su política de clusters, y cabe asimismo destacar el significativo papel de las cooperativas industriales y manufactureras (Ahedo, 2006). En la Comunidad Valenciana, su inicial política de red de Institutos Tecnológicos (IMPIVA) orientados a las pymes de sus distritos industriales sectoriales perdió estatus político e institucional con los gobiernos regionales del PP desde 1995. Ahedo y Brunet (2010) 
aplican el concepto de bienes colectivos de competitividad local para identificar los factores que pueden llevar a pymes locales a ser innovadoras o competitivas en España. El sistema catalán de innovación, específicamente, es un sistema híbrido en el que conviven dos modelos (Ahedo et al., 2014). Por un lado, un modelo STI formal en base a su desarrollado sistema de investigación, con un alto nivel de formalización política e institucional. Por el otro lado, un modelo DUI informal, en base a una estructura sectorial comprensiva y poco especializada, una alta presencia de pymes manufactureras sin relaciones densas y unas redes informales de interacción y relación. Este DUI informal no ha gozado de una institucionalización política ni de organizaciones estables para hacerlo más formalizado y efectivo. En Cataluña, además de una falta de políticas industriales, las políticas de innovación no se han orientado de forma efectiva a promover la capacidad innovadora de su tejido empresarial (Ahedo, 2018).

Según las experiencias internacionales de los estudios de nivel micro, los factores internos y organizativos de las pymes han recibido una menor atención teórica (Callejón y Ortún, 2009). El papel de los trabajadores en la innovación ha sido destacado por la propuesta de innovación basada en los empleados y el aprendizaje en el lugar de trabajo (Høyrup, y Møller, 2012). Desde una teoría interactivocultural de la organización, se subraya la importancia de la interacción simbólica y comunicativa entre los miembros de la organización, desde las precondiciones para la interacción constituidas en las prácticas y rutinas organizativas y en las políticas laborales y de contratación. En el caso de las pymes, su reducido tamaño puede convertirse en una ventaja si se sabe gestionar en base a la proximidad y la interacción cara a cara. Hay dos aspectos centrales. Primero, con respecto a la gestión de una pyme, es relevante observar si la gestión está en manos de una persona profesional independiente o de la familia propietaria, aunque una solución intermedia consiste en que las nuevas generaciones de propietarios adquieran un mayor nivel de formación en gestión. Segundo, el sistema o cultura de relaciones: la interacción entre dirección y empleados resulta crítica, y especialmente entre la dirección y los empleados de calificación media, que en muchos casos pueden tener estudios técnicos de secundaria superior.

Con relación al nivel microempresarial u organizativo en España, el tamaño medio de las pymes en general es relativamente más pequeño que la media europea, aunque un poco más alto que la media de muchos países del sur de Europa como Italia. En España hay regulaciones que limitan el crecimiento en tamaño de las empresas, como puede ser el estatus fiscal y laboral para las empresas de más de 50 empleados, lo que desanima muchas empresas familiares o de gestión poco profesionalizada en sus proyectos de crecimiento. Las pymes, a pesar de su reducido tamaño, tienen la posibilidad de ser dinámicas e innovadoras. En un estudio en base a encuestas-entrevistas, Aragón-Sánchez y Sánchez-Marín (2005) concluyen que de los 15 principales obstáculos o barreras para la innovación y la competitividad en las pymes, los más importantes están asociados a los costes y los menos significativos son los asociados con la resistencia de gestores/empleados. Ahedo (2010), en base a los datos de las encuestas sobre las condiciones de 
trabajo de la Eurofound, encuentra algunos rasgos con la posibilidad potencial de mejorar la capacidad de innovación en las pymes españolas, como son el ambiente positivo y comunitario en la relación entre colegas, y el trato recibido por los superiores. Varios estudios sobre las pymes del País Vasco y Navarra han enfatizado la importancia de la organización de trabajo y el papel de los empleados de nivel medio con formación técnica en las prácticas de innovación (Olazarán et al., 2009; Lavía, et al., 2016). En suma, las pymes industriales españolas tienen la potencialidad de ser innovadoras. Desarrollar y hacer efectivas esas potencialidades es tarea de las instituciones públicas y civiles.

En nuestro estudio sobre la innovación escondida de las pymes, construimos varios conceptos y categorías para entender este nivel micro de las pymes y su vínculo con las redes-cadenas de valor y suministro. En concreto, se han elaborado las siguientes nociones: a) marcos discursivo-cognitivos, entendidos como contextos culturales y discursivos que enmarcan las estrategias y prácticas concretas; b) planificación y gestión de la innovación, que incluye las decisiones estratégicas sobre la innovación y sobre las mejoras incrementales; c) estrategias y repertorios de innovación, que derivadas de los factores anteriores se refieren a las actividades reales y cotidianas relacionadas con la innovación y las mejoras.

\section{Diseño metodológico}

Partimos de la hipótesis según la cual las formas de gestión de las redes y cadenas globales de valor, por parte de las corporaciones que las controlan, influyen y condicionan los repertorios de innovación de las pymes que están insertas en las mismas. La innovación en pymes manufactureras tiende a tener un carácter de mejora incremental, y se conceptualiza como innovación escondida. Esta innovación escondida se organiza en función de una serie de marcos discursivo-cognitivos, formas de gestión, y estrategias y repertorios de prácticas de innovación, que tienen una clara naturaleza social y relacional dentro de las empresas y respecto a las redes-cadenas de provisión-valor sectoriales, tanto a nivel local-regional, sectorial, nacional y global.

Para estudiar las formas típicas de vinculación de las pymes en las redes y cadenas globales de valor, así como sus repertorios típicos de innovación, empleamos un diseño metodológico cualitativo. Para ello, nos basamos en entrevistas a directivos y propietarios de pymes, junto con observación en las empresas. Las entrevistas las efectuamos sobre la base de una muestra estructural (Ibáñez, 1988). No pretendemos obtener una representatividad extensiva, sino la búsqueda de sujetos y casos que reproduzcan, en una escala experimental, prácticas empresariales y discursos sobre innovación propios de las pymes industriales (mediante el análisis de las pymes en Cataluña). Reconstruimos prácticas típicas de innovación de las pymes que nos permiten dar un paso más en la comprensión de este fenómeno, especialmente sus dinámicas organizativas. Sobre la base del conocimiento elaborado a partir de la muestra, podemos proyectar los tipos de prácticas analizados hacia un conjunto mayor, bajo el supuesto de homogeneidad interna de la posición estructural de las pymes. 
Las entrevistas y las visitas a las empresas se efectuaron en el año $2011^{2}$. Para alcanzar la representatividad estructural, la muestra está conformada por directivos de 22 pymes industriales (de Cataluña). Consideramos que los criterios organizativos y los discursos empresariales sobre la innovación que observamos son representativos del sector, y nos permiten comprender rasgos típicos del comportamiento y las perspectivas empresariales sobre dicha temática. En la muestra hay perfiles que responden a diferentes situaciones económicas, lo cual nos permite estudiar distintos tipos de prácticas innovadoras. Concretamente, 10 empresas forman parte de grupos económicos (nacionales y extranjeros), y 12 son empresas individuales, de naturaleza familiar y sociedades anónimas. Las empresas se encuentran insertas en el sector metalmecánico y electrónico, con fuerte peso en componentes y materiales. La mitad de ellas elaboran productos propios, es decir, son dueñas de sus diseños. La otra mitad elabora productos diseñados en gran parte por sus clientes, mediante subcontrataciones. Algunas combinan ambas modalidades. Una parte de la muestra destina su producción al mercado nacional, y otras tienen elevados niveles de exportación. Doce empresas son proveedoras de firmas globales, siete son proveedoras de TIER 1 o 2 en cadenas de subcontratación, tres pymes operan exclusivamente con otras pymes, y otras tres operan también con el sector público (algunas combinan esta última modalidad con alguna de las dos primeras) ${ }^{3}$.

Utilizamos como metodología de análisis la Teoría Fundamentada (Glaser, 1992). Strauss y Corbin (1990) sostienen que la Teoría Fundamentada es útil para entender un fenómeno social sobre el cual se quiere profundizar en su comprensión. A partir de ella, elaboramos una serie de conceptos teóricos y proposiciones que nos permiten identificar los procesos sociales básicos de la innovación desde una mirada sociológica. En este sentido, partimos de las aportaciones de la literatura sobre la innovación en pymes y desarrollamos una serie de conceptos que nos permiten conocer con mayor precisión los distintos tipos de innovación y sus diferentes prácticas organizativas.

En suma, el estudio aquí presentado aspira a contribuir al conocimiento sociológico de las prácticas que influyen en la mayor o menor innovación en las pymes en Cataluña, dentro de su contexto micro, meso y macro.

\section{Marcos discursivo-cognitivos y tipos principales de innovación}

Reconstruimos los marcos cognitivos típicos de los empresarios y/o gerentes de pymes sobre innovación (incremental) en productos y en procesos. Por marcos cognitivos entendemos esquemas conceptuales e interpretativos que permiten

2. La configuración y el funcionamiento de los mercados no ha cambiado sustantivamente desde entonces. La información obtenida relacionada con los incentivos y las lógicas de funcionamiento continúa siendo útil para elaborar repertorios típicos de prácticas innovadoras de las pymes industriales.

3. En el anexo 1 detallamos las características de las pymes según el origen del capital, la cantidad de trabajadores, la pertenencia (o no) a un grupo económico mayor, el sector de actividad y el tipo de productos que ofrecen. 
a los individuos y grupos (en este caso, empresarios y mandos gerenciales) comprender la realidad y los contextos en los que se desenvuelven. La forma como un empresario o un mando gerencial adquiere, registra, transforma y utiliza la información del entorno resulta fundamental para tomar decisiones económicas. Los marcos compartidos facilitan las interacciones entre organizaciones porque permiten disponer de interpretaciones comunes sobre lo que acontece. Los consideramos lentes con las cuales se perciben las oportunidades y las posibilidades de innovación. A partir de ello, podemos reconstruir prácticas y repertorios de innovación en las empresas.

En todos los casos analizados, las pymes innovadoras llevan a cabo innovaciones incrementales, que constituyen pequeñas o medianas mejoras continuas de productos o procesos, aplicadas al desarrollo de un bien a lo largo del tiempo. Las innovaciones radicales, en gran medida, están fuera de su alcance dado que requieren un proceso dirigido a través de laboratorios de $\mathrm{I}+\mathrm{D}$, y se aplican desarrollos en ciencia básica (Lam, 2002).

Sobre la innovación en productos encontramos dos variantes, que están en función de la forma en que se insertan las pymes en la red-cadena de valor y suministros. Por una parte, la innovación como adaptación creativa a la demanda específica del cliente: «Tenemos que hacer una adaptación de un producto que desarrolla el cliente, y nos pide que quiere esto de esta forma o de la otra» (empresa 21). La idea general la desarrolla el cliente, que suele ser una firma grande, y las empresas pymes acompañan ese desarrollo adaptando componentes específicos. La presión por innovar que tiene la pyme proviene de la necesidad de acompañar esa idea externa de acuerdo con sus recursos propios, utilizando conocimientos tácitos.

Por otra parte, la innovación en producto como desarrollo o concepto propio. En esta variante, el espíritu emprendedor se expresa en una creatividad propia de la pyme que permite diversificar sus productos/servicios. No surge de ideas originalmente provistas por el cliente, sino que es resultado de desarrollos internos e iniciativas autónomas de la firma: «En este caso desarrollamos un producto más conceptual, que diseñamos nosotros en nuestras oficinas técnicas» (empresa 11). Aquí el incentivo por innovar proviene de la percepción que los empresarios tienen de las oportunidades de mercado. Un directivo nos ilustra:

Tenemos que innovar para permanecer en el mercado. (...) Si queremos tener bases firmes, tenemos que investigar a largo plazo porque hay saltos tecnológicos que se van dando en el mundo y hay que estar en estos saltos (empresa 12).

En esta variante, la innovación es resultado de un mecanismo de decodificación de las necesidades de los clientes y de las posibilidades propias, y remite a la cercanía cognitiva de la empresa con el entorno.

Con respecto a las innovaciones en procesos, se percibe como resultado de las presiones de los clientes y/o del mercado. El cliente ofrece una oportunidad de trabajo a la pyme (contratando por un servicio o producto) a un determina- 
do precio. Para asumirlo con un margen de rentabilidad, la pyme está obligada a ser innovadora en procesos para reducir costes.

La empresa quiere sobrevivir, porque el precio de venta lo pone el mercado, y entonces si quiere seguir tiene que tener un coste inferior al mercado, y para esto hay que intentar aumentar la productividad» (empresa 19).

La innovación de procesos asume, en el discurso, un carácter obligatorio o forzado porque es impuesta por los clientes, dada la posición subordinada de la pyme en la red-cadena de valor y suministros.

Dentro de este discurso de la necesidad (de innovaciones en procesos), encontramos matices según el tipo de empresa. En las firmas que elaboran productos estandarizados, y que innovan solo en procesos, la innovación significa la posibilidad de bajar el coste laboral mediante la adaptación de tecnología externa (adquirida en el mercado) a los procesos productivos internos.

Toda la innovación es introducir procesos o herramientas que existen en el mercado a nuestro propio proceso. Es lo que más acostumbramos a hacer las empresas de España. Te doy un ejemplo: la simulación de llenado. En el 99 introdujimos las $3 \mathrm{D}$, introdujimos un tercer almacén automático que es para el acabado de piezas. De la línea van automáticamente al almacén; este almacén lo distribuye a las líneas de acabado o de control. Y cuando acaban, también automáticamente, van a este almacén y en este almacén se va haciendo la lista (empresa 14).

El discurso resalta que las empresas son innovadoras si logran conectar los conocimientos propios con los productos tecnológicos y bienes de capital adquiridos en el mercado, lo que requiere capacidad de absorción por parte de las pymes. Esta conexión favorece el objetivo último de la innovación en este perfil de pymes: aumentar la productividad del trabajo y/o reducir su coste

Las materias primas son las mismas para todo el mundo. Y para nosotros el $70 \%$ es materia prima, su coste no lo podemos bajar; pero el $30 \%$ de mano de obra hay que intentar bajarlo continuamente (empresa 17).

En esta variante resulta más visible que la innovación empresarial puede estar impulsada por el conflicto laboral, en tanto modifica la relación entre salarios y beneficios.

Un segundo componente discursivo de la innovación en procesos consiste en que la innovación equivale a mejorar dichos procesos productivos. Suelen ser discursos de firmas subcontratistas, que no innovan en productos ni hacen $\mathrm{I}+\mathrm{D}$ interna: «Para nosotros la innovación... no es inventar, sino es mejorar» (empresa 8). La mejora continua de procesos y rutinas de trabajo implica la integración racional de todos los aspectos organizativos y logísticos de la empresa.

Para mandar piezas a Vigo tuvimos que diseñar un contenedor donde poner las piezas, que para nosotros fue un esfuerzo de diseño específico. La innovación 
abarca todo el proceso productivo, desde la entrada de un pedido hasta que se expide. O sea, innovamos para mejorar, no inventamos nada (empresa 1).

Un tercer componente discursivo de la innovación de procesos la vincula con la renovación de las estrategias comerciales, que implica la búsqueda de nuevos mercados a partir de las nuevas aplicaciones de los productos. El discurso de la innovación resalta la importancia de las nuevas formas de comercialización, tales como asistir a ferias internacionales, aprovechar las nuevas oportunidades de ventas por internet, etcétera.

\section{La planificación y la gestión de la innovación}

En este subapartado estudiamos la gestión interna de la práctica innovadora de las pymes. Específicamente, analizamos las características de la planificación y de los procesos de toma de decisiones sobre las innovaciones (especialmente en productos). En las pymes industriales, la planificación de la innovación responde a prácticas que oscilan entre semiestructuradas (es decir, que responden a esquemas basados en rutinas) y aleatorias (que carecen de esquemas rutinarios).

a) Prácticas semiestructuradas y poco formalizadas. En pymes que cuentan con departamento de I+D y habitualmente forman parte de un grupo económico mayor, la planificación tiene un carácter semiestructurado no formalizado. En estos casos existe, por parte de la dirección, una relativa planificación a medio plazo que estima los objetivos y los recursos para la innovación, y que funciona como una declaración inicial de intenciones. El siguiente relato ilustra esta variante típica.

Tenemos un plan estratégico entre comillas, pero no hay documento escrito. Es un plan estratégico que siempre se pone en la mesa, y que está en constante evolución, pero no hay un documento escrito. No funcionamos así, no funcionamos como una gran empresa que tiene esto establecido por la cúpula. Respecto al presupuesto para $\mathrm{I}+\mathrm{D}$, cada proyecto tiene una carga en cuanto a personal, dedicación, tiempo. Lo que son inversiones de I+D se van viendo con la evolución del proyecto, no se establecen a priori. Cuando llega la necesidad es cuando se discute realmente la compra, el desarrollo o la adquisición de lo que necesitamos (empresa 3).

La planificación sistemática y documentada no es posible para estas empresas, que están sujetas a los imperativos de una demanda (y unos ingresos) difícil de prever. Constituye una declaración de intenciones sujeta a posibles cambios, internos y externos, que la obliga a mantener una posición relativamente flexible en sus proyectos de producción. Así, las inversiones en innovación son el resultado de un compromiso variable entre la necesidad y las disponibilidades de recursos. Por tanto, las prácticas de innovación requieren un alto grado de pragmatismo. Las innovaciones se basan en investigaciones y desarrollos ad-hoc, adecuados a sus realidades y posibilidades. 
b) Prácticas aleatorias de innovación. En las pymes que son subcontratistas, la planificación en innovación suele ser menor aún. El hecho de estar sujetos a proyectos de clientes mayores no genera los incentivos suficientes para planificar de forma sistemática la investigación en desarrollos propios. Por ello, la planificación no existe como tal y los esfuerzos de innovación tienen un carácter aleatorio. Un directivo nos ilustra esta modalidad.

No hay una organización para la innovación, no hay reuniones de creatividad, esto no está organizado, sucede informalmente. El leit es el mercado, que nos indica que deberíamos tener este producto, y luego lo van hablando hasta que aterriza en ingeniería (empresa 22).

Y con respecto a la planificación para la innovación...

Va surgiendo sobre la marcha, no hay un proceso; sí que hay ideas, pero un punto que no está formalizado. Hemos intentado formalizarlo, pero el propietario es el propietario y si las ideas salen de él, hay que preguntarle a él (empresa 5).

Por tanto, vemos que la innovación es aleatoria y carece de sistematicidad. Constituye una idea general que se va adaptando y concretando en función de las circunstancias del mercado y/o de la situación interna de la empresa. Las decisiones se toman sobre la marcha, según la evolución del mercado.

Tenemos reuniones anuales en las que discutimos sobre cosas nuevas que podemos hacer, pero te diría que la mayoría de las innovaciones que hacemos provienen de distintas situaciones y de cómo reaccionamos a ellas, y a partir de aquí surge un nuevo camino (empresa 20).

Una vez establecido que la planificación puede ser semiestructurada y/o aleatoria, analizamos de qué manera se toman las decisiones de inversión en las pymes. Elaboramos los tres modos típicos en que se toman las decisiones sobre las prácticas innovadoras.

a) Modelo colegiado. Las decisiones colegiadas responden a un modelo aplicable a las firmas medianas en las que participan diversas áreas e intereses internos:

El círculo de innovación está formado por los directores de todas las áreas, porque así damos con todas las visiones de la idea. Aparte, se desarrolla la idea para que todos la entendamos de la misma forma y se unifique la visión. Se hace una ficha, y nos tenemos que basar en la ficha para votarla. ¿Cómo la votamos? En base a los criterios estratégicos que están alineados con la estrategia de la compañía (empresa 4).

Otro directivo nos ilustra la misma lógica:

Lo que hacemos aquí es que hay un equipo de dirección, que analiza los proyectos que entran, RRHH, finanzas, marketing, operaciones, calidad, ingenie- 
ría... Nos sentamos, y de todos estos proyectos decidimos los que van y los que no van, después se los pasamos a un ingeniero y mira que recursos necesita... (empresa 12).

La práctica innovadora por la que finalmente se van a apostar recursos se decide mediante acuerdos y negociaciones entre las partes directivas de la empresa.

b) Modelo vertical participativo. Las decisiones de inversión en innovaciones se toman en la dirección general de la empresa. Por su parte, los responsables de las diferentes áreas productivas participan en la elaboración de propuestas y en rondas de consultas, y posteriormente se encargan de implementar las decisiones asumidas por la dirección general. Lo observamos en pymes que participan en grupos económicos mayores, donde las decisiones se toman en la cúspide del grupo.

Hay varios foros donde se discuten estas cosas. Tenemos reuniones de investigación, reuniones estratégicas anuales, reuniones de comité ejecutivo. El planning process es anual, que es la reunión alta del comité ejecutivo. Es la de mayor nivel, donde se toman las decisiones más importantes, pero allí no se toman las decisiones de si vamos a comprar un pequeño equipo de laboratorio. Eso es más de reuniones bimensuales y se habla de cosas de este tipo, hay diferentes foros, pero no lo hace el departamento de $\mathrm{I}+\mathrm{D}$, se hace siempre en reuniones donde hay un representante de dirección o del director general (empresa 3).

El mismo esquema también lo registramos en pymes que no forman parte de grupos mayores, que tienen una estructura más sencilla, y que también disponen de espacios de discusión aunque el nivel decisorio esté concentrado en la cúpula de la organización. Mostramos un ejemplo de esta variante:

Hay un equipo interdepartamental que está formado por el director técnico, por un product manager, que es la persona que conoce el producto y el mercado en el que va, por el director de calidad y por el director de fabricación. Estas cuatro personas normalmente son las que diseñan la estrategia del producto cuando lo tenemos encima de la mesa, y cuando la estrategia está diseñada. Yo soy el director y dejo hacer, pero al final valoro si esa propuesta será correcta o no (empresa 17).

c) Modelo vertical decisional. Es aplicable a pequeñas empresas, que tienen una estructura más simple, organizada sobre una lógica puramente vertical de toma de decisiones, concentrada en la dirección general. El resto de la plantilla sigue los lineamientos decididos por el director general. Un empresario nos ilustra:

Como os he planteado, nosotros somos una plantilla de 28 personas. Tenemos una cierta estructura indirecta, pero vamos a decir que somos todos operativos, que estamos al pie del cañón y estamos al día a día. No tenemos una corporate; la única corporate que hay soy yo (empresa 21). 
Cuando la planificación de la innovación es semiestructurada, implica que se ha discutido previamente la orientación general de la firma, aunque está sujeta a cambios. En estos casos, el proceso de toma de decisiones sobre innovaciones responde al modelo colegiado o al modelo vertical participativo. En los casos de pymes que pertenecen a grupos económicos mayores, se sigue el modelo vertical participativo.

Las pymes que no planifican la innovación suelen ser de un tamaño menor y aquí la innovación resulta aleatoria. Cuando se toman decisiones de inversión sobre procesos/productos innovadores, el modelo más coherente resulta el vertical decisional, porque es el que más se adapta a una estructura subordinada a empresas de mayor tamaño. En definitiva, si relacionamos ambos aspectos de la gestión de la innovación (la planificación y la toma de decisiones), vemos que las pymes que tienen cierto nivel de planificación se corresponden con modelos de decisión participativos, mientras que las pymes cuyas innovaciones son aleatorias se estructuran en procesos más decisionales. A grandes rasgos, tenemos un modelo de gestión semiplanificado/participativo y un modelo de gestión de la innovación aleatorio/decisional.

\section{Estrategias y repertorios de prácticas innovadoras}

En este apartado analizamos las estrategias y los repertorios de prácticas innovadoras de las pymes industriales con la siguiente secuencia analítica: a) primero estudiamos los modos típicos de formación de ideas innovadoras; b) analizamos las formas de circulación y los mecanismos de comunicación de ideas innovadoras; c) combinando los dos aspectos anteriores, elaboramos los modos típicos en que se forman las ideas innovadoras en las pymes; d) se describen las diferentes relaciones interempresariales en su sector y cadena de valor; e) en base a los pasos anteriores, identificamos las principales estrategias de innovación; f) finalmente subrayamos los dos grandes tipos de repertorios de prácticas innovadoras. Por repertorio entendemos capacidades aprendidas que se traducen en prácticas habituales y recurrentes, y que, desde nuestro criterio, dependen de la forma en que surgen; se combinan las ideas innovadoras y las estrategias empleadas por las firmas.

\subsection{Formación de ideas innovadoras}

Las ideas innovadoras surgen de un contexto de relaciones de intercambio comunicativo entre agentes económicos. Pueden originarse en distintos lugares y circular en diversos sentidos. Dichos intercambios comunicativos ocurren, en la mayoría de las pymes, en la cadena de valor. Constituye un proceso reflexivo y dialógico, basado en dinámicas de abajo-arriba no lineares, informales y multidireccionales de aprendizaje y de flujos de información. En este sentido, analizamos los recorridos típicos por los que circulan las ideas que promueven las prácticas innovadoras en las pymes.

Una primera variante típica de la circulación de ideas que incentivan innovaciones es aquella en la que el cliente le plantea ciertas necesidades a la pyme. 
A continuación, la pyme analiza internamente las posibilidades de desarrollar el producto o resolver la necesidad del cliente. Las negociaciones y evaluaciones las llevan a cabo la dirección general, financiera y comercial de la pyme (o los directivos responsables de estos temas), y la implementación tecnológica de esa innovación se organiza a través de las oficinas técnicas de las pymes y los clientes:

Gran parte de las innovaciones vienen de las necesidades de los clientes. Por ejemplo, vendemos una de nuestras máquinas ${ }^{4} y$, después de usarla uno o dos años, el cliente nos dice que le iría bien que hagamos tal cosa, u otra máquina que tenga otra funcionalidad que necesitaría el cliente. Entonces cogemos esta idea y analizamos si se puede hacer, si es viable comercialmente (empresa 20).

Los inputs de información provienen del mercado, en el sentido de que son los clientes quienes efectúan determinados pedidos o indican tendencias, que luego son adaptadas creativamente en las oficinas técnicas, de manera negociada con el cliente, a las posibilidades de las pymes. Constituyen una relación típica que, desde el punto de vista de la pyme, supone un recorrido descendente cliente-pyme, en el sentido de graficar el origen y la dirección de la demanda de innovaciones a lo largo de la red-cadena de valor y suministros.

Esta variante expresa una tendencia en las grandes empresas a delegar en la red de sus proveedores pymes funciones que antes desarrollaban autónomamente en el interior de su organización. En esta lógica, las pymes tienen incidencia en el desarrollo y diseño del producto, pero como subcontratados. En tal colaboración, la pyme propone modificaciones, pequeñas innovaciones incrementales con respecto al original (adaptación creativa) para que se pueda fabricar en condiciones viables para ellos, lo cual compromete más a la pyme y le da espacio para cierta innovación propia.

En una segunda variante típica, las innovaciones de las pymes provienen del intercambio comunicativo con sus propios proveedores

A veces una innovación viene provocada por un proveedor, que piensa hacer una innovación de una determinada manera, y entonces nos sondea con un nuevo producto que después podemos aplicar y adaptar a nuestra producción, y eso nos obliga a innovar en otras cosas (empresa 6).

Constituyen un recorrido ascendente proveedor-pyme, con origen en el proveedor. En este caso, la comunicación de una nueva idea tiene originalmente un sentido vertical ascendente, desde el proveedor a la pyme. Pero a continuación la dinámica innovadora es interna a esta última firma, y la mejora o el producto final es relativamente independiente de la innovación hecha por el proveedor. Las instancias de desarrollo de estas ideas, además de los aportes de las oficinas técnicas y/o la dirección de operaciones, son las

4. Panificadoras, en este ejemplo. 
sesiones de creatividad entre integrantes de diferentes sectores de la pyme, de los círculos de calidad u otras instancias comunicativas similares. Constituye una modalidad típica de circulación de ideas que redundan en mejoras de productos y procesos.

Una tercera variante típica ocurre cuando, por propia iniciativa, la pyme sondea al cliente sobre la posibilidad de un nuevo producto que incorpora una innovación. Las posibilidades innovadoras las visualiza y desarrolla la propia pyme, tras la decodificación de las necesidades del mercado o entorno. Dicha decodificación se organiza a través de la comunicación entre la dirección general, financiera, comercial, y las oficinas técnicas, y son luego consultadas con los clientes para determinar su viabilidad comercial. Las ideas innovadoras surgen internamente de las oficinas técnicas de las pymes, pero existen relaciones sociales previas entre la pyme y el entorno que proveen los insumos con los cuales se elaboran ideas. Ilustramos esta práctica con el siguiente pasaje:

Nosotros intentamos que nuestro director técnico sea una persona que esté fuera, porque es un poco como el comercial. Es alguien que te tiene que traer mucho know-how. Tiene que estar fuera, tiene que ir a simposios, tiene que ir a ver empresas, tiene que estar en grupos de investigación, porque allí es donde va a coger el conocimiento. Aquí dentro difícilmente lo consiga. Sí que te puedes conectar a internet y allí hay mucha información, pero cuando estás fuera es cuando conoces a la gente y cuando se dan oportunidades (empresa 10).

Expresan relaciones típicas en la cadena de valor que representan un recorrido ascendente pyme-cliente, con origen en la pyme. Constituye una modalidad de circulación de ideas que redundan en nuevos productos o mejores prestaciones.

Un cuarto recorrido típico es una variante del anterior, en el que las ideas innovadoras surgen del vínculo entre agentes del sistema y las pymes, y a continuación esta negocia comercialmente con el cliente. La diferencia se encuentra en que, en este último caso, el desarrollo de la idea surge de vínculos formalizados con el entorno del sistema de innovación, mientras que en el tercero las ideas surgen en el interior de la organización de la pyme, utilizando aportaciones informales del entorno. En la cuarta variante, el vínculo con el sistema de innovación es más estable y formalizado. Suele ser una variante que utilizan las pymes más dinámicas en innovación, con mayor tamaño y recursos relativos, que aprovechan las oportunidades del sistema regional de innovación para desarrollar ideas de manera conjunta, mediante la colaboración e intercambio con agentes externos - centros tecnológicos, universidades, asesorías privadas, etcétera- Constituyen una variante propia de empresas altamente capitalizadas que innovan en productos propios y que forman parte de grupos económicos.

A este tipo de recorrido de ideas innovadoras lo denominamos recorrido reticular pyme/entorno, porque las ideas innovadoras surgen de relaciones con la red tecnológica de apoyo a la innovación, y no de la cadena de valor. En esta variante, las ideas surgen de los diversos vínculos que pueden establecerse en 
la red de agentes del sistema, pero el ámbito de la empresa que articula dichas ideas es el departamento de $\mathrm{I}+\mathrm{D}$, que constituye un nodo clave del funcionamiento de las redes. Una vez definidas allí las líneas centrales de la innovación, se terminan de implementar mediante las oficinas técnicas y los círculos de calidad de las pymes. Constituye una variante típica de circulación de ideas innovadoras que suelen traducirse en mejoras de productos, nuevos productos o mejoras de procesos.

\subsection{Mecanismos de comunicación y circulación de ideas innovadoras}

Las ideas y las prácticas de innovación se desarrollan sobre vínculos de confianza y de comunicación entre los agentes implicados. Los mecanismos de comunicación entre empresas y agentes pueden favorecen la colaboración y reducir la incertidumbre. Los mecanismos de comunicación pueden tener un grado mayor o menor de formalización y de rutinización.

Por un lado, los mecanismos informales son los distintos tipos de vínculos comunicativos con el entorno, que se dan de manera aleatoria y no sistemática. Es decir, no se asientan en rutinas preestablecidas para tal fin.

Las ideas vienen de la comunicación con el mundo externo. El de marketing que habla con el cliente y detecta una necesidad. Otros se dan cuenta de que el cliente tiene una dificultad para hacer una determinada pieza. Las ideas pueden surgir de muchos sitios, pero siempre en contacto con el mundo externo (empresa 12).

Los mecanismos de comunicación informales permiten el intercambio de información entre los agentes y monitorear sus productos, pero de manera aleatoria. Existen mecanismos más formalizados, que consisten en vínculos de comunicación relativamente sistemáticos con el entorno, basados en rutinas establecidas y en una interacción organizada, y que tienen la potencialidad de inducir ideas y prácticas que se traduzcan en productos innovadores. Un entrevistado nos relata:

Hacemos días de innovación con proveedores, hacemos días de innovación con clientes y vamos a hablar con un cliente, invitamos a todos sus ingenieros, nosotros exponemos lo que tenemos y entonces allí también establecemos esta relación y nos enteramos de las necesidades que tienen. Hacemos lo que llamamos line box, que es entrar en las líneas de montaje de los clientes y miramos a ver por donde tienen potencial de ahorrar tiempo y dinero en sus fijaciones (empresa 11).

Por otro lado, los mecanismos formales se basan en rutinas preestablecidas: reducen la incertidumbre entre los agentes, hacen más confiables sus relaciones y, además de mejorar el intercambio de información y el monitoreo de los productos y las prácticas de los agentes, constituyen instancias que favorecen la deliberación y la coordinación. 


\subsection{Procesos típicos de formación de ideas innovadoras}

Los procesos típicos de formación de ideas innovadoras pueden ser observados a partir de combinar los recorridos más habituales de dichas ideas en la cadena de valor y los mecanismos de comunicación. Así podemos establecer distintas combinaciones típicas que reflejan diferentes prácticas innovadoras.

Por un lado, tenemos el flujo de ideas y propuestas que parte del cliente hacia la pyme (de acuerdo con los cánones, podríamos denominarlo recorrido descendente cliente-pymes) y, por otro lado, el que surge de los proveedores hacia la pyme (recorrido ascendente proveedores-pyme). Ambos están basados en adaptaciones creativas de demandas de los clientes, en el primer caso, o en nuevos materiales/aplicaciones de proveedores, en el segundo. Las dos variantes se corresponden con mecanismos informales de comunicación. No se basan en rutinas preestablecidas, sino que surgen de iniciativas exógenas a las pymes, y están fuera de su control. En este sentido, los procesos de formación de ideas son aleatorios porque derivan de fuentes externas que no controla la pyme.

Por otro lado, el flujo de ideas y propuestas que parte de la pyme hacia sus clientes (recorrido ascendente pyme-cliente) y el flujo de ideas y propuestas que circula bidireccionalmente entre la pyme y su entorno institucional (recorrido reticular entorno-pyme) se basan de manera más habitual en mecanismos formales y/o estables de comunicación, dado que son posibles debido a la existencia de ciertas rutinas que implican un mayor nivel de estructuración de las relaciones sociales. Representan un modo de formación de ideas innovadoras más estructurado y basado en rutinas. Constituye una variante típica de formación de ideas innovadoras que se corresponde más estrechamente con la innovación en tanto desarrollo propio de la pyme.

Más específicamente, hay un modo aleatorio de formación de ideas innovadoras, dado que las relaciones entre las empresas no son sistemáticas. Dentro de esta variante, observamos dos subtipos. Uno que está dinamizado por los clientes de las pymes, mediante relaciones informales y no rutinarias, y que se traduce en nuevos productos o prestaciones que demanda el cliente. Un segundo subtipo aleatorio está dinamizado por los proveedores de las pymes, también mediante relaciones informales, y suele traducirse en mejoras de productos ya existentes y mejoras de procesos.

Por otra parte, hay un modo más estructurado de formación de ideas innovadoras, dado que se basa en rutinas, y tiene dos subtipos. El primero es un modo estructurado de formación de ideas innovadoras dinamizado por la propia pyme, mediante relaciones sistemáticas con sus clientes, y se traduce en nuevos productos y/o prestaciones ofrecidos al cliente. El segundo subtipo es un modo estructurado de formación de ideas innovadoras, dinamizado por las redes del entorno de las pymes, mediante relaciones sistemáticas. Se traduce en el desarrollo de nuevos productos, prestaciones y/o en mejoras de procesos. Estos procesos constituyen los mecanismos específicos por los cuales las pymes logran absorber, asimilar y capitalizar las posibilidades de innovación. 


\subsection{Relaciones interempresariales}

A continuación reconstruimos las estrategias más habituales de las pymes para establecer relaciones y vínculos entre sí dentro de su sector, cadena de valor y entorno local:

a) Articulaciones sistemáticas. Alianzas interempresariales dentro del sector para potenciar recursos colectivos: alianzas, acuerdos de complementación, colaboraciones, clusters. Estas colaboraciones se dan entre pymes del mismo sector. La cooperación entre pymes en ciertas líneas de negocios se visualiza como una opción racional, a pesar de que en otras líneas exista competencia entre ellas. Constituye una variante poco extendida en sistemas de innovación de bajo desarrollo e integración.

b) Articulaciones puntuales. Alianzas de corto plazo en la cadena de valor (con proveedores y clientes). El discurso que favorece esta práctica se basa en la percepción de ventajas económicas para defender las posiciones de la pyme en el mercado. Son puntuales porque la alianza desarrolla un producto específico, pero no supone un horizonte de trabajo conjunto entre empresas a largo plazo, sino resolver una demanda específica. Esta variante tiene una presencia más extendida de pymes en sistemas de innovación de bajo desarrollo e integración.

c) Colaboraciones semiforzadas. Alianzas puramente formales, incentivadas por las subvenciones que las pymes pueden obtener del sector público si se presentan proyectos de trabajo conjunto entre diversas empresas. Tiene un carácter semiforzado porque debajo de esta formalidad no existe una práctica de colaboración real, un intercambio genuino de recursos que consolide un clima de confianza mutua. Esta variante más bien es una forma de encubrir una estrategia no cooperativa real.

d) Finalmente están las pymes que optan por estrategias individualistas y no cooperativas. Esta estrategia está motivada por tres causas fundamentales. Primera, por una concepción patrimonialista de la organización, por la cual existe una dificultad de orden cultural entre sus propietarios para concebir las empresas del sector como posibles aliados en ciertas circunstancias. Constituye una variante típica de empresas familiares pequeñas, con nivel bajo-medio de profesionalización de la gestión. Las innovaciones se conciben, en estos casos, como elaboraciones que surgen de vínculos comunicativos dentro del círculo de confianza patrimonialista. Segunda, por una concepción individualista, que refleja una inserción aislada de la pyme, debido a la ausencia de capital social y falta de información sobre las posibilidades de articulación con otras empresas. En esta variante no hallamos necesariamente una concepción patrimonialista de la empresa, sino una estrategia pobre construida sobre la debilidad del capital social de la dirección de la empresa. De forma similar al caso anterior, la innovación surge de un intercambio de ideas dentro de un círculo limitado de integrantes de la empresa. Tercera, por limitaciones estructurales a la cooperación dadas por la imposibilidad de articulación 
productiva. Ocurre en empresas que elaboran bienes básicos y solo innovan en procesos, y por tanto no tienen incentivos para colaborar unas con otras.

\subsection{Estrategias típicas de innovación}

La mayoría de las pymes industriales elaboran productos intermedios o componentes en relación con clientes generalmente grandes. Dado que la mayoría de las innovaciones de las pymes industriales implican relaciones entre agentes que participan en la cadena de valor, diferenciamos cuatro estrategias típicas.

a) Reforzar el valor añadido. Es una estrategia orientada a las necesidades específicas de los clientes, a partir de la detección de sus demandas o necesidades potenciales. Se centra en la elaboración de productos en series cortasmedianas pero con mayor valor añadido, lo que requiere del desarrollo de tecnologías, know-how, I+D, formación interna, etcétera. Esta opción estratégica descarta la fabricación de grandes cantidades a bajos precios. Como ilustración, un directivo nos relata:

Con un señor que tiene una dimensión 100 veces mayor que nosotros y que tiene dos fábricas en China y una en Brasil, es muy difícil competir. Por precio no podemos competir. Por tanto, cada año tenemos que hacer alguna innovación que le demuestre al cliente que le aportamos un valor muy superior al de únicamente vender un producto (empresa 8 ).

Constituye una estrategia que es coherente con un proceso de formación de ideas innovadoras estructurado y basado en rutinas (desarrollado en el apartado 6.3.).

b) Especialización y/o complementariedad con grandes clientes. Es una variante de lo anterior. Esta estrategia se basa en la incorporación a redes comerciales controladas por grandes firmas, ajustando sus capacidades internas en función de las estrategias de externalización de las grandes empresas. La iniciativa innovadora no surge solo de la pyme, sino de propuestas de los clientes que, mediante mecanismos de comunicación entre las firmas, se van desarrollando hasta alcanzar un acuerdo sobre el producto. Es una estrategia previamente negociada entre las firmas. Un empresario del sector de maquinarias nos ilustra esta estrategia:

En el mundo había un solo fabricante de este tipo de máquinas, que es alemán, y hacía gran volumen. Estamos hablando de inversiones a partir de 600 mil a 1 millón de euros, que solamente puedes amortizar o justificar para producciones de 70 millones o 80 millones de piezas al año. Pero en el año 85 desarrollan una versión de máquina que nos permite integrarnos con unas nuevas piezas fabricadas en volúmenes medios, y que a este fabricante no le interesa desarrollar internamente. Pues a partir de aquí, durante estos 25 años de historia hemos desarrollado tres generaciones de máquinas, y ahora estamos desarrollando la cuarta generación (empresa 21). 
Constituye una estrategia coherente con lo que hemos denominado modo aleatorio de formación de ideas innovadoras en el apartado 6.3., dado que las iniciativas provienen de los propios clientes.

c) Diversificación de productos y clientes mediante la disminución del riesgo económico que implica depender de un único producto, cliente o segmento del mercado, y apuesta por la diversificación. Esta estrategia presenta cuatro modalidades. En primer lugar, la identificación de nuevos sectores y nichos de mercado, mediante proponer a los clientes aplicaciones novedosas de productos propios, elaborar nuevos productos, etcétera. Estas búsquedas son iniciativas de las pymes, dada la inestabilidad de los mercados en los que habitualmente operan. Son búsquedas basadas en el ensayo y error, y representan actitudes proactivas.

Nos introdujimos en el tema ferroviario hace pocos años, antes estábamos en otro sector. Fue un poco gracias a descubrir nuevas aleaciones, y poco a poco hemos ido abriendo esta línea de negocio nueva. Antes estábamos más centrados en el tema eléctrico o tubos. El mercado de tubo ahora va a peor, porque existe el tubo de plástico, y estamos intentando sacar ideas para nuevas aplicaciones para tubo de cobre. La propia innovación te abre mercados (empresa 7).

\section{Otro directivo nos amplia:}

Vamos buscando un poco más a ciegas, porque no sabes en qué te estás moviendo, en qué mercado, en qué sector... pero vas buscando aplicaciones donde tu producto genere un valor añadido que no esté allí en el mercado. Entonces hemos empezado a arañar el sector biomédico, que es un sector muy complejo, regulado, difícil. Hemos empezado a tocar sectores de composites para sistemas de frenado, hemos empezado a tocar sistemas para pilas de combustibles de sistemas muy porosos de filtraje, purificadores... Son sectores muy diferentes a los que nosotros nos acostumbramos a mover (empresa 3).

En segundo lugar, la búsqueda de nuevos mercados y clientes dentro del mismo sector. Un ejemplo de un directivo:

Nuestra empresa comienza en un taller pequeño, con dos personas soldando tubos de escape. A partir de ahí, crece. Yo te diría que hasta 2004 esto era una empresa local/comarcal del Bages que había crecido mucho. Y a partir de ahí, sí que se empieza con dos líneas de trabajo muy claras: internacionalización. En 2003 se empiezan a hacer cosas con China, y en 2004 se abre la planta en China y se empieza a pasar de innovación de procesos a producto, vamos construyendo sobre eso (empresa 1).

En tercer lugar, la colocación de nuevos productos o servicios al mismo cliente. Permite diversificar los riesgos de la dependencia de una gama limitada de productos, pero mantiene la dependencia hacia pocos clientes. Un entrevistado nos ilustra la situación: 
Los ingenieros de Van der Lande, en Veghel nos mandan unos planos, pero cuando los industrializamos no salen al precio que nos piden. Entonces, primero lo vemos con nuestros ingenieros y luego incorporamos centros tecnológicos que nos ayudan a desmontarlo todo y volverlo a montar, una ingeniería inversa para nuestro cliente para que aquello pueda salir más barato. Y el próximo paso es ver qué cosas compra nuestro cliente y que a nosotros nos gustaría venderle. Estamos intentando desarrollar un producto propio para venderle (empresa 5).

En cuarto lugar, renovar las estrategias comerciales, que implican utilizar los nuevos canales de comunicación, como las nuevas oportunidades de ventas por internet, las ferias internacionales, etcétera. Estas estrategias basadas en diversificar productos y clientes son consistentes con procesos de formación de ideas innovadoras que hemos denominado modo estructurado de formación de ideas innovadoras, porque se basa en rutinas más o menos preestablecidas, y que implican búsquedas autónomas de alternativas por parte de las pymes.

d) Partner de una gran empresa. Una cuarta estrategia general que visualizamos consiste en llevar a cabo acuerdos estratégicos con alguna gran empresa, y comprometerse en el desarrollo tecnológico de esta. Implica la inserción de las pymes en nuevos mercados, especialmente internacionales, aunque no de forma autónoma sino conducida por los grandes clientes de referencia. El proceso conlleva el pasaje de ser proveedores de una gran empresa multinacional a nivel español a ser proveedor de la misma a nivel global, basado en la fidelización mencionada.

La crisis, en ciertas empresas y mucho en las multinacionales, ha provocado una reestructuración a nivel mundial de todas las empresas. Entonces cuando nosotros trabajábamos para la multinacional X pero para su sede en España, hicimos esta estrategia y pudimos empezar a trabajar por la multinacional X pero a nivel mundial. Y es muy distinto trabajar para una multinacional a nivel de Alemania, o a nivel España. Entonces esto fue una puerta que se nos abrió (empresa 17).

Las prácticas de fidelización son claves en las estrategias de innovación de productos específicos y/o bienes intermedios para grandes empresas. Esta estrategia es consistente con modos aleatorios de formación de ideas innovadoras, que surgen de iniciativas autónomas de la empresa líder. Pero también es consistente con modos estructurados de formación de ideas innovadoras, basados en un feed-back más o menos estabilizado entre la empresa líder y la pyme.

\subsection{Dos grandes repertorios de prácticas innovadoras}

De la combinación de estas estrategias de innovación, por un lado, y de los modos de formación de ideas innovadoras (aleatorios y estructurados), elaboramos los repertorios de prácticas innovadoras de las pymes industriales, que responden a dos grandes líneas. 
Por un lado, repertorios de prácticas innovadoras autónomas, basados en procesos relativamente sistemáticos o estructurados de producción de ideas innovadoras con la finalidad de reforzar el valor añadido, la ampliación de productos y clientes, y mejorar su posición de relación en la red-cadena. Responden a formas de articulación/colaboración también sistemáticas entre empresas, especialmente en la red-cadena de producción-valor.

Por otro lado, repertorios de innovación subordinada a los clientes, basados en procesos relativamente aleatorios de formación de ideas innovadoras, mediante los cuales refuerzan la opción de insertarse en las redes de subcontratación de los grandes clientes y, en ocasiones, en la fidelización hacia los mismos. Asimismo, lo que denominamos repertorios de prácticas innovadoras autónomas responde de manera más coherente a un modelo de gestión semiplanificado/participativo, orientado al desarrollo de innovaciones propias. Mientras que el repertorio de innovación subordinada a los clientes es consistente, en términos típicos, con un modelo de gestión de la innovación aleatorio/decisional, y basado en adaptaciones creativas de las demandas de los clientes.

\section{Conclusiones}

El artículo ha ofrecido un análisis en profundidad de las principales formas de innovar por parte de las pymes industriales de tecnología media y baja en Cataluña. La investigación cualitativa nos permitió elaborar conceptos y categorías típicos, junto con sus diferentes combinaciones (marcos cognitivos, planificación y gestión de la innovación, estrategias y repertorios de prácticas innovadoras). Dichos conceptos y categorías nos facilitaron la compresión de las formas sociales que adquieren las prácticas innovadoras. Las estrategias y los repertorios de innovación que hemos elaborado y analizado constituyen los procedimientos específicos por los cuales las pymes se articulan e intentan mantenerse en las redes-cadenas de valor y suministros, y son una de las aportaciones del artículo.

A partir del caso catalán, se pueden extraer dos tipos de generalizaciones: a) sobre la realidad local de las pymes manufactureras; b) sobre la realidad global. Suponemos que las estrategias y repertorios de prácticas innovadoras en pymes industriales dan cuenta de prácticas más o menos comunes a otros entornos sociales similares, en los que las pymes están articuladas y estructuralmente relacionadas en crecientes redes-cadenas de valor y suministros. Estos dos tipos de generalizaciones los presentamos en los tres niveles teóricos propuestos (micro, meso y macro), tal como desarrollamos a continuación.

A nivel micro organizativo, para el cual desarrollamos el conjunto de categorías conceptuales, y con relación a los marcos discursivo-cognitivos, existe un discurso que concibe la innovación como una práctica específica, incremental y contingente. A la vez, como algo necesario y obligado para las empresas si quieren mantenerse en las redes-cadenas de valor y suministros. Con respeto a la planificación y la gestión interna de la innovación, se han encontrado 
dos tipos de prácticas de planificación: semiestructuradas y aleatorias. Y tres modelos de toma de decisión sobre las prácticas innovadoras: colegiado, vertical participativo y vertical decisional. En lo que atañe a las estrategias de prácticas innovadoras, se han encontrado cuatro tipos principales: reforzar el valor añadido, especialización y/o complementariedad, diversificación de productos y clientes, y constituirse en partner de una gran empresa. De la combinación de estos elementos, se han elaborado dos repertorios típicos de innovación: las prácticas innovadoras subordinadas a los clientes, por un lado, y las prácticas innovadoras autónomas. Debido a las características de las pymes en Cataluña, entre estas firmas las prácticas innovadoras subordinadas a los clientes tienen una mayor extensión cuantitativa, mientras que las prácticas innovadoras autónomas se presentan en una proporción menor de empresas. No obstante, el carácter cualitativo de este artículo nos permite solo dar cuenta de sus características internas y de los tipos de prácticas innovadoras.

A nivel meso, en el entorno catalán (y español), los elementos de un sistema de innovación que más relevancia tienen para las pymes son el dinamismo de su organización interna y las relaciones con otras empresas. Tienen una incidencia menor, en términos de impacto directo sobre las pymes, las políticas públicas de apoyo a la innovación, el sistema financiero, las estructuras de I+D y el sistema formativo. Esto remite a la debilidad de los bienes colectivos de competitividad local. Por este motivo, en el caso de este perfil de pymes, probablemente los sistemas sectoriales de innovación adquieren una mayor relevancia explicativa que los sistemas regionales, debido a la debilidad relativa de las políticas públicas y de las instituciones locales. En este contexto, podemos pensar que los modos de gestión de las redes-cadenas de valor y suministro, controladas por las grandes empresas lead, ejercen un papel destacado sobre los repertorios de prácticas innovadoras de las pymes; papel que se ve reforzado por la debilidad de los bienes colectivos de competitividad local.

De acuerdo con la línea que plantea Bair (2008), la estructura cambiante del sistema capitalista mundial permite explicar la fuerza y debilidad de las distintas regiones y sus instituciones de apoyo a la innovación. Los nodos más importantes de las redes-cadenas de valor y suministros tienden a ubicarse en las regiones centrales del sistema mundo. Ello permite ejercer un poder de influencia diferencial a las grandes empresas y a las regiones que concentran la acumulación de valor. Consideramos que, bajo este esquema, de todas maneras podemos utilizar la tipología de Gereffi et al. (2005) sobre las formas de gobernanza de las redes-cadenas de valor y suministros, como marco dentro del cual inscribir los repertorios de prácticas innovadoras que elaboramos en este artículo. El modelo de Gereffi et al., presentado en el apartado teórico, nos parece adecuado para relacionarlo con nuestra tipología, porque los casos analizados en nuestra investigación operan en un contexto de debilidad de las instituciones públicas y de bienes colectivos de competitividad local, y las estrategias de control de las grandes empresas adquieren una incidencia mayor.

Siguiendo el modelo de Gereffi et al., un conjunto de las pymes estudiadas encaja en los tipos de gobernanza de las redes-cadenas valor y suministros 
basados en transacciones sin interacción, y de captura, por parte de las grandes corporaciones, a través del dominio de marcas, diseños, marketing, etcétera, y que ofrecen pocas posibilidades a las pymes para innovar. Aquí se encuentran aquellas pymes que innovan de manera aleatoria a través de la incorporación de tecnología externa para bajar costes y también mediante estrategias de fidelización; sus repertorios de prácticas innovadoras son de carácter aleatorio y, en especial en el primer caso, se establecen a través de procesos de decisión muy concentrados en los empresarios individuales.

En los tipos de gobernanza corporativa de las redes-cadenas de valor y suministros denominados relacionales y modulares, existen más oportunidades para las pymes de innovar porque hay más interacción con las grandes empresas. Aquí se englobarían las pymes que combinan mecanismos formales e informales de comunicación de ideas innovadoras, y que se corresponden en mayor medida con repertorios de prácticas autónomas de innovación, porque se basan en rutinas de las pymes que buscan diversificar productos y clientes. Finalmente, el tipo de gestión vertical o jerárquico de las redes-cadenas de valor, por parte de las grandes corporaciones, es consistente con las estrategias de pymes basadas en articulaciones sistemáticas y estables, y con mecanismos más formalizados de comunicación entre la pyme y el cliente que controla comercialmente la producción final. Aquí las oportunidades para innovar son más elevadas. Desde esta perspectiva, por tanto, las oportunidades para realizar innovaciones, para las pymes catalanas (y españolas), dependen fundamentalmente del modo de gestión de las cadenas de valor por parte de los compradores globales. Las estrategias y los repertorios de innovación que hemos analizado constituyen los procedimientos específicos por los cuales las pymes se articulan e intentan mantenerse en las cadenas y redes de valor controladas por grandes grupos empresariales.

Observamos una relativa debilidad estructural de las pymes manufactureras a la hora de relacionarse con las organizaciones dominantes de sus respectivos sectores económicos, dadas las características del sistema de innovación. Como vemos, los modos de gestión de las redes-cadenas de valor y suministro por parte de las grandes empresas, sostenidas en entramados institucionales específicos de los territorios y regiones de sus actividades centrales y periféricas, tienen un papel destacado sobre los repertorios de prácticas innovadoras de las pymes subcontratadas o vinculadas comercialmente con ellas. En Cataluña, las oportunidades de innovación de las pymes industriales (y los repertorios de innovación de las mismas) están altamente condicionadas por las estrategias de las grandes empresas líderes, en un contexto de políticas e instituciones públicas que apoyan débil y escasamente los repertorios autónomos de innovación de pymes. La debilidad de los bienes colectivos de competitividad local y la fuerte influencia que ejercen las grandes empresas (que controlan las redes-cadenas de valor y suministro) sobre los repertorios de prácticas innovadoras de las pymes expresarían el posicionamiento subordinado de la región dentro de la estructura del sistema mundo que organiza la producción capitalista global. 
A nivel macro, España ocupa una posición marginal en el grupo central de países dentro de la división internacional de la producción. Las políticas de apoyo a las pymes han tenido un lento recorrido institucional, con baja coordinación y eficacia, lo que podría explicar en parte los problemas de las empresas españolas para operar de manera más virtuosa en las redes verticales de provisión. A nivel global, el alto poder y la discrecionalidad de las grandes empresas lead que operan de forma transnacional deberían ser objeto de debate político y de consideración de posibles regulaciones que intenten hacer más virtuoso el sistema productivo global. En concreto, que ayude las pymes locales a relacionarse de una manera más virtuosa en las redes-cadenas de valor y suministros.

\section{Referencias bibliográficas}

AHEDO, Manuel (2006). «Business systems and cluster policies in the Basque Country and Catalonia (1991-2003). The construction of 'Industry-Government' collaboration». European Urban and Regional Studies, 13 (1), 5-19. <https://doi.org/10.1177/0969776406059227>

- (2010). «Exploring the innovative potential of SMEs in Spain». Transfer: European Review of Labour and Research, 16 (2), 197-209. <https://doi.org/10.1177/1024258910364307>

- (2018). «The construction of unbalanced innovation policies in Catalonia (Spain)». International Journal of Innovation and Regional Development, 8 (2), 179-195. <https://doi.org/10.1504/ijird.2018.092098>.

AHEDO, Manuel; PIZZI, Alejandro y BelZuneGuI, Ángel (2014) Innovación y desarrollo. El caso de Cataluña. Valencia: Tirant Lo Blanc.

AHEDO, Manuel y BRUNET, Ignasi (2010). «Desarrollo local, pymes innovadoras y bienes colectivos de competitividad». Revista Española de Sociología, 14, 75-91.

AMABLE, Bruno (2003). The diversity of modern capitalism. Oxford: Oxford University Press.

Arundel, Anthony; Lorenz, Edward; Lundvall, Bengt-Å. y Valeyre, Antoine (2007). «How Europe's economies learn: A comparison of work organization and innovation mode for the EU-15». Industrial and corporate change, 16 (6), 11751210. <https://doi.org/10.1093/icc/dtm035>.

ARUNDEL, Anthony; Bordoy, Catalina y Kanerva, Minna (2008). Neglected innovators: How do innovative firms that do not perform ReD innovative? Results of analysis of the Innobarometer 2007 Survey, INNO-Metrics Thematic Paper, no 215.

ARAGÓN-SÁNCHEZ, Antonio y SÁNCHEZ-MARín, Gregorio (2005). «Strategic orientation, management characteristics, and performance: A study of Spanish SMEs». Journal of Small Business Management, 43 (3), 287-308. <https://doi.org/10.1111/j.1540-627x.2005.00138.x>

ASHEIM, Bjorn y COENEN, Lars (2005). «Knowledge bases and regional innovation systems: Comparing nordic clusters». Research policy, 34 (8), 1173-1190. $<$ https://doi.org/10.1016/j.respol.2005.03.013>

AsheIm, BJorn; SMITH, Helen y Oughton, Christine. (2010). «Regional innovation systems. Theory, empirics and policy». Regional Studies, 45 (7), 875-891. <https://doi.org/10.1080/00343404.2011.596701> 
BABONES, Salvatore (2015). «What is world-systems analysis? Distinguishing theory from perspective». Thesis Eleven, 127 (1), 3-20. <https://doi.org/10.1177/0725513615575324>

BAIR, Jennifer (2008). «Analysing global economic organization: Embedded networks and global chains compared». Economy and Society, 37 (3), 339-364. <https://doi.org/10.1080/03085140802172664>

BOYER, Robert (2005) «How and why capitalisms differ». Economy and Society, 34 (4), 509-557. $<$ https://doi.org/10.1080/03085140500277070>

CAllejón, María y OrTún, Vicente (2009). «La caja negra de la dinámica empresarial». Revista de Investigaciones Regionales, 15, 167-189.

Crouch, Colin (2005). Capitalist diversity and change: Recombinant governance and institutional entrepreneurs. Oxford: OUP Oxford. <https://doi.org/10.1093/acprof:oso/9780199286652.001.0001>

Crouch, Colin; Le Galès, Patrick; Trigilia, Carlo y VoelzKow, Helmut (2001). Local production systems in Europe: Rise or demise? Oxford: Oxford University Press.

Crouch, Colin; SCHröder, Martin y VoelzKow, Helmut (2009). «Regional and sectoral varieties of capitalism». Economy and Society, 38 (4), 654-678. <https://doi.org/10.1080/03085140903190383>

EDWARDS, Tim; DELBRIDGE, Rick y Munday, Max (2005). «Understanding innovation in small and medium-sized enterprises: A process manifest». Technovation, 25 (10), 1119-1127. <https://doi.org/10.1016/j.technovation.2004.04.005>

GLASER, Barney (1992). Basics of grounded theory analysis: Emerge vs. Forcing. Mill Valley, California: Sociology Press.

Gereffi, Gary; Humphrey, John y STurgeon, Timothy (2005). «The governance of global value chains». Review of International Political Economy, 12 (1), 78-104. <https://doi.org/10.1080/09692290500049805>

Hansen, Povl y SERIN, Göran (1997). «Will low technology products disappear?: The hidden innovation processes in low technology industries». Technological Forecasting and Social Change, 55 (2), 179-191. <https://doi.org/10.1016/s0040-1625(97)89490-5>

IBÁÑEZ, Jesús (1988). «Perspectivas de la investigación social: El diseño en las tres perspectivas». En: FerRANDO, Manuel García; IBÁÑEZ, Jesús y Alvira, Francisco (eds.). El análisis de la realidad social: Métodos y técnicas de investigación, 17-48. Madrid: Alianza Editorial.

Kristensen, Peer y LiLjA, Kari (2011). Nordic capitalisms and globalization: New forms of economic organization and welfare institutions. Oxford: Oxford University Press. <https://doi.org/10.1093/acprof:oso/9780199594535.001.0001>

Høyrup, Steen y Møller, Kirsten (2012). Employee-driven innovation: A new approach. Londres: Palgrave Macmillan. $<$ https://doi.org/10.1057/9781137014764>

Lavía, Cristina; OTERo, Beatriz; Albizu, Eneka y Olazaran, Mikel (2016). «Perfiles empresariales y participación de los trabajadores con cualificaciones intermedias en actividades de innovación: el caso del País Vasco». Revista Española de Sociologia, 25 (3), 367-386.

<https://doi.org/10.22325/fes/res.25.3.2016.367> 
LAM, Alice (2002). "Alternative societal models of learning and innovation in the knowledge economy». International Social Science Journal, 54 (171), 67-82. $<$ https://doi.org/10.1111/1468-2451.00360>

LeE, Sunjoo; PARK, Gwangman; Yoon, Byungun y PARK, Jinwoo (2010). «Open innovation in SMEs. An intermediated network model». Research policy, 39 (2), 290-300. <https://doi.org/10.1016/j.respol.2009.12.009>

LundVAlL, Bengt-Å. (2007). «National innovation systems. Analytical concept and development tool». Industry \& Innovation, 14 (1): 95-119. <https://doi.org/10.1080/13662710601130863>

Lundvall, Bengt-A.; Rasmussen, Palle y LorenZ, Edward (2008). «Education in the learning economy: A European perspective». Policy Futures in Education, 6 (6): 681-700. $<$ https://doi.org/10.2304/pfie.2008.6.6.681>

MalerbA, Franco (2004). Sectoral systems of innovation. Concepts, issues and analysis of six major sectors in Europe. Cambridge: Cambridge University Press. <https://doi.org/10.1017/cbo9780511493270>

Nelson, Robert (1993). National Innovation Systems. A comparative analysis. Oxford: Oxford University Press.

Olazaran, Mikel y OTERO, Beatriz (2009). «La perspectiva del Sistema Nacional y Regional de Innovación. Balance y recepción en España». Arbor: Ciencia, Pensamiento y Cultura, 738, 767-779. <https://doi.org/10.3989/arbor.2009.738n1051>

Olazaran, Mikel; AlBizu, Eneka y OTERO, Beatriz (2009). Innovación en las pequeñas y medianas empresas industriales guipuzcoanas. Universidad del País Vasco, Servicio Editorial.

REVISTA ESPAÑOLA DE SOCIOLOGÍA (2016). «Monográfico sobre sistemas de innovación regional y formación profesional». Volumen $25, \mathrm{n}^{\circ} 3$. $<$ https://doi.org/10.22325/fes/res.25.3.2016.313>

STRAUSS, Anselm y Corbin, Juliet (1990). Basics of qualitative research: Grounded Theory, procedures and techniques. Beverly Hills: Sage Publications.

WhiTLEY, Richard (1999). Divergent capitalisms: The social structuring and change of business systems. Oxford: Oxford University Press. 


\section{Anexo de empresas entrevistadas}

\begin{tabular}{|c|c|c|c|}
\hline Empresa 1 & $\begin{array}{l}\text { nacional; } 250 \text { trabajadores; } \\
\text { forma parte de un grupo } \\
\text { empresarial español; automoción; } \\
\text { componentes de automóviles }\end{array}$ & Empresa 12 & $\begin{array}{l}\text { extranjera; } 90 \text { empleados; forma } \\
\text { parte de un grupo empresarial } \\
\text { extranjero; materiales metálicos; } \\
\text { productos metálicos para cone- } \\
\text { xiones eléctricas }\end{array}$ \\
\hline Empresa 2 & $\begin{array}{l}\text { nacional; } 241 \text { trabajadores; } \\
\text { forma parte de un grupo empre- } \\
\text { sarial español; ferroviario; compo- } \\
\text { nentes para máquinas ferroviarias }\end{array}$ & Empresa 13 & $\begin{array}{l}\text { nacional; } 85 \text { trabajadores; no } \\
\text { forma parte de un grupo econó- } \\
\text { mico; automoción; componentes } \\
\text { para frenos }\end{array}$ \\
\hline Empresa 3 & $\begin{array}{l}\text { extranjera; } 230 \text { empleados; } \\
\text { forma parte de un grupo } \\
\text { extranjero; automoción; } \\
\text { componentes de automóviles }\end{array}$ & Empresa 14 & $\begin{array}{l}\text { nacional; } 84 \text { empleados; no } \\
\text { forma parte de un grupo eco- } \\
\text { nómico; automoción; discos de } \\
\text { frenos }\end{array}$ \\
\hline Empresa 4 & $\begin{array}{l}\text { nacional; } 220 \text { trabajadores; } \\
\text { forma parte de un grupo económi- } \\
\text { co extranjero; automoción/cons- } \\
\text { trucción; fabricación de dumpers }\end{array}$ & Empresa 15 & $\begin{array}{l}\text { nacional; } 70 \text { empleados; no } \\
\text { forma parte de un grupo econó- } \\
\text { mico; maletas para herramientas } \\
\text { industriales }\end{array}$ \\
\hline Empresa 5 & $\begin{array}{l}\text { nacional; } 200 \text { trabajadores; forma } \\
\text { parte de un grupo económico } \\
\text { nacional; productos mecánicos } \\
\text { y máquinas; transportadoras para } \\
\text { aeropuertos }\end{array}$ & Empresa 16 & $\begin{array}{l}\text { nacional; } 59 \text { empleados; no } \\
\text { forma parte de un grupo econó- } \\
\text { mico; automoción; moldeado de } \\
\text { vidrios para automóviles }\end{array}$ \\
\hline Empresa 6 & $\begin{array}{l}\text { nacional; } 180 \text { empleados; no } \\
\text { forma parte de un grupo económi- } \\
\text { co nacional; maquinaria; herrajes } \\
\text { de toldos }\end{array}$ & Empresa 17 & $\begin{array}{l}\text { nacional; } 56 \text { trabajadores; no } \\
\text { forma parte de un grupo econó- } \\
\text { mico; estampación y deforma- } \\
\text { ción metálica; componentes para } \\
\text { motocicletas }\end{array}$ \\
\hline Empresa 7 & $\begin{array}{l}\text { nacional; } 160 \text { trabajadores; } \\
\text { forma parte de un grupo } \\
\text { económico nacional; materiales } \\
\text { metálicos; productos de cobre }\end{array}$ & Empresa 18 & $\begin{array}{l}\text { nacional; } 50 \text { trabajadores; no } \\
\text { forma parte de un grupo econó- } \\
\text { mico; productos mecánicos y } \\
\text { maquinaria; máquinas textiles }\end{array}$ \\
\hline Empresa 8 & $\begin{array}{l}\text { nacional; } 140 \text { empleados; } \\
\text { forma parte de un grupo } \\
\text { nacional; matricería; reductores } \\
\text { de velocidad }\end{array}$ & Empresa 19 & $\begin{array}{l}\text { nacional; } 48 \text { trabajadores; } \\
\text { no forma parte de un grupo eco- } \\
\text { nómico; maquinarias; reparación } \\
\text { de máquinas de automoción }\end{array}$ \\
\hline Empresa 9 & $\begin{array}{l}\text { nacional; } 125 \text { trabajadores; } \\
\text { forma parte de un grupo econó- } \\
\text { mico nacional; productos mecá- } \\
\text { nicos; máquinas tragaperras y } \\
\text { parquímetros }\end{array}$ & Empresa 20 & $\begin{array}{l}\text { nacional; } 40 \text { trabajadores; no } \\
\text { forma parte de un grupo eco- } \\
\text { nómico; productos mecánicos, } \\
\text { máquinas; máquinas para hornos }\end{array}$ \\
\hline Empresa 10 & $\begin{array}{l}\text { nacional; } 100 \text { empleados; } \\
\text { no forma parte de un grupo } \\
\text { económico; productos de } \\
\text { iluminación; luminarias }\end{array}$ & Empresa 21 & $\begin{array}{l}\text { nacional; } 30 \text { empleados; no } \\
\text { forma parte de un grupo eco- } \\
\text { nómico; materiales metálicos; } \\
\text { estampación de productos metá- } \\
\text { licos, terminales de conexión } \\
\text { eléctrica. }\end{array}$ \\
\hline Empresa 11 & $\begin{array}{l}\text { extranjera; } 100 \text { trabajadores; } \\
\text { forma parte de un grupo económi- } \\
\text { co extranjero; automoción; piezas } \\
\text { para automóviles }\end{array}$ & Empresa 22 & $\begin{array}{l}\text { nacional; } 28 \text { empleados; no } \\
\text { forma parte de un grupo eco- } \\
\text { nómico; productos mecánicos; } \\
\text { matrices para llantas de coches }\end{array}$ \\
\hline
\end{tabular}


